NBER WORKING PAPER SERIES

\title{
WAS THERE A RIVERSIDE MIRACLE? A FRAMEWORK FOR EVALUATING MULTI-SITE PROGRAMS
}

\author{
Rajeev Dehejia \\ Working Paper 7844 \\ http://www.nber.org/papers/w7844 \\ NATIONAL BUREAU OF ECONOMIC RESEARCH \\ 1050 Massachusetts Avenue \\ Cambridge, MA 02138 \\ August 2000
}

The author acknowledges support from the Connaught Fund (University of Toronto), and thanks the Manpower Demonstration Research Corporation for making the data from the Greater Avenues for Independence Demonstration available. Gary Chamberlain, Siddhartha Chib, Barton Hamilton, Caroline Hoxby, Guido Imbens, Larry Katz, Geert Ridder, and seminar participants at Columbia University, Washington University, the Johns Hopkins University, the NSF Econometrics and Statistics Symposium on Quasi-Experimental Methods are gratefully acknowledged for their comments. The views expressed herein are those of the author and not necessarily those of the National Bureau of Economic Research.

(C) 2000 by Rajeev Dehejia. All rights reserved. Short sections of text, not to exceed two paragraphs, may

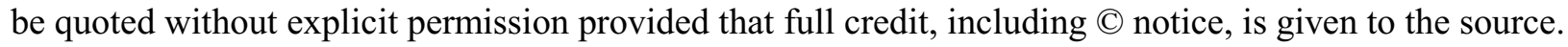


Was There a Riverside Miracle? A Framework for Evaluating

Multi-Site Programs

Rajeev Dehejia

NBER Working Paper No. 7844

August 2000

JEL No. C11, I38, J31

\begin{abstract}
This paper uses data from the Greater Avenues for Independence (GAIN) initiative to discuss the evaluation of programs that are implemented at multiple sites. Two frequently used methods are to pool the data or to use fixed effects (an extreme version of which estimates separate models for each site). The former approach, however, ignores site effects. Though the latter estimates site effects, it lacks a framework for predicting the impact in subsequent implementations of the program (e.g., will a new implementation resemble Riverside or Alameda?). I develop a model for earnings that lies between these two extremes. For the GAIN data, I show that most of the differences across sites are due to differences in the composition of participants. I show also that uncertainty regarding predicting site effects is important; when the predictive uncertainty is ignored, the treatment impact for the Riverside sites is significant, but when we consider predictive uncertainty, the impact for the Riverside sites is insignificant. Finally, I demonstrate that the model is able to extrapolate site effects with reasonable accuracy, when the site for which the prediction is being made does not differ substantially from the sites already observed. For example, the San Diego treatment effects could have been predicted based on observable site characteristics, but the Riverside effects are consistently underestimated.
\end{abstract}

\author{
Rajeev Dehejia \\ Department of Economics \\ Columbia University \\ 420 W.118 ${ }^{\text {th }}$ Street, Room 1022 \\ New York NY 10027 \\ and NBER \\ dehejia@columbia.edu
}




\section{Introduction}

This paper discusses the problem of evaluating and predicting the treatment impact of a program that is implemented at multiple sites. Many programs operate at, and are evaluated at, multiple sites, e.g., NSW, JTPA, New Chance, and Greater Avenues for Independence (GAIN), which is studied in this paper. Two kinds of differences can emerge across sites: differences in the composition of participants and differences in the treatment (or how it is administered). The former is relatively easy to address if a sufficient number of the participants' characteristics are observed. The latter leads to more difficult questions: are observations on participants at other sites relevant in determining the treatment impact at a given site? And if the program is implemented again, how can we predict the impact at a new site? These questions are important because they influence the interpretation of many evaluations.

One standard method of dealing with site-specific effects is to use a fixed-effects model, or more generally to estimate separate models for each site. To the extent that cross-site differences are administrative or qualitative, this would be a valid approach to estimating the impact in the original implementation. However, it limits us to thinking of subsequent implementations of the program as being identical to one of the original sites, because there is no framework to account for predictive uncertainty regarding the value of the fixed effect or site-specific model. Another solution would be to pool the data. This treats units as exchangeable conditional on observable variables, ignoring site effects, and allows us to predict the outcome in subsequent implementations. Alternatively we can think of pooling as averaging over site effects and predicting the outcome averaged over 
subsequent implementations. Neither interpretation allows us to consider how the site effects would vary in subsequent implementations.

This paper explores the middle ground between these methods through the use of hierarchical modeling (see Chamberlain and Imbens [1996], Geweke and Keane [1996], and Rossi, McCulloch, and Allenby [1995] for other applications of these methods). Hierarchical modeling is somewhat familiar in the frequentist literature through the related concept of meta-modeling (see Cooper and Hedges [1994]). Meta-modeling involves linking the outcomes of separate studies on the same topic through an overarching model. It can also be used to model site effects; for example, Card and Krueger (1992) estimate cohort and state-of-birth specific returns to schooling and then use a meta-model to relate these to measures of school quality. The method adopted in this paper is a Bayesian version of meta-modeling.

There are three layers to the model. The first layer consists of separate regression models for each site. The second layer links the coefficients of the site models through a regression-type meta-model. The third layer consists of prior distributions for the unknown parameters. Thus, a hierarchical model combines features of the fixed-effect and pooled models, but also allows for intermediate models. First, compared to standard fixed (or random) effects, it allows for site-specific estimation of all coefficients, not just the constants. Second, participants across sites are not assumed to be exchangeable conditional on individual characteristics, but instead are assumed to be exchangeable within sites conditional on individual characteristics. Third, we use a prior distribution to model the extent to which we believe that site-effects are drawn from a common 
distribution; i.e., the extent to which coefficients should be "smoothed" across sites, or observations from one site should influence our estimates in other sites.

This approach is applied to data from the Greater Avenues for Independence (GAIN) Demonstration, a labor training program implemented in six California counties at 24 sites (see Riccio, et al., [1996]). Much attention in the GAIN program focused on the Riverside county implementation, which was viewed as being highly successful and distinct from other counties (see, for example, Nelson [1997]). From the perspective of GAIN, the interest is in discovering the extent to which a hierarchical model succeeds in capturing these site effects which have been viewed as being primarily qualitative in nature. We focus on three issues. First, to what extent does pooling the data across all sites obscure site effects? Second, if we imagine re-implementing a GAIN-type program, would we be able to predict the site effects based on the observable characteristics of each site, and how important is predictive uncertainty? Third, how well can the model extrapolate to sites that have not been observed? These questions will be addressed below.

Previous papers on multi-site evaluation issues are Heckman and Smith (1996), Hotz, Imbens, and Mortimer (1998), and Hotz, Imbens, and Klerman (2000). Heckman and Smith analyze the sensitivity of experimental estimates to the choice of sites used in the analysis and to different methods of weighting the pooled data. The paper establishes that there is significant cross-site variation in the data from the JTPA evaluation. Hotz, Imbens, and Mortimer analyze the importance of site effects in the GAIN data using the key insight that, even if there is heterogeneity in the treatment available at each site, control groups excluded from the program at other sites should still be comparable if 
there are no site effects. They are able to control for site effects in control group earnings, but not treatment group earnings, suggesting the existence of treatment heterogeneity across sites. Thus, the model used in this paper allows for site effects in both treatment and control earnings. Hotz, Imbens, and Klerman is complementary to the current paper. Like the current paper, they use regression adjustment to control for differences in the composition of program participants, but unlike the current paper they do not use site characteristics. They do, however, have six additional years of posttreatment earnings data.

The paper is organized as follows. Section 2 describes the GAIN program. Section 3 discusses key features of the GAIN data. Section 4 outlines the hierarchical model. Section 5 presents the results, and Section 6 concludes.

\section{The Data}

The GAIN program began operating in California in 1986, with the aim of "increasing employment and fostering self-sufficiency" among AFDC recipients (see Riccio, et al., [1994]). In 1988, six counties -- Alameda, Butte, Los Angeles, Riverside, San Diego, and Tulare -- were chosen for an experimental evaluation of the benefits of GAIN. A subset of AFDC recipients (single parents with children aged six or older and unemployed heads of two-parent households) were required to participate in the GAIN experiment (see Table 1). ${ }^{1}$

Potential participants from the mandatory group were referred to a GAIN orientation session when they visited an Income Maintenance office (either to sign up for

\footnotetext{
${ }^{1}$ This discussion draws on Dehejia (1999).
} 
welfare or to qualify for continued benefits). ${ }^{2}$ As a result, the chronology of the data and subsequent results are in experimental time, rather than calendar time. No sanctions were used if individuals failed to attend the orientation sessions. However, once individuals started in the GAIN program, sanctions were used to ensure their ongoing participation. At the time of enrollment into the program, a variety of background characteristics were recorded for both treatment and control units including: demographic characteristics; results of a reading and mathematics proficiency test; and data on ten quarters of pretreatment earnings, AFDC, and food stamp receipts. ${ }^{3}$

Of those who attended the orientation session, a fraction was randomly assigned to the GAIN program, ${ }^{4}$ and the others were prohibited from participating in GAIN. ${ }^{5}$ Each of the counties randomized a different proportion of its participants into treatment, ranging from a 50-50 split in Alameda to an 85-15 split in San Diego (see Table 1). Because assignment to treatment was random, the distribution of pre-treatment covariates is balanced across the treatment and control groups. In terms of the chronology of data gathering, "experimental" time (which I also refer to as "post-experimental" or "posttreatment" time) begins when individuals attend the GAIN orientation session. The early stages of experimental time thus coincide with the education and training of GAIN participants. $^{6}$

\footnotetext{
${ }^{2}$ In some counties AFDC recipients were allowed to volunteer into the GAIN program, but these units are not included in the public use sample.

${ }^{3}$ Data on AFDC and Food Stamp receipts were taken from each county's welfare records. Data on earnings were taken from the California State Unemployment Insurance Earnings and Benefits Records. Other background characteristics were taken from California's client information ("GAIN-26") form. See Riccio, et al., (1994).

${ }^{4}$ The randomization was (as far as we know) independent of pre-treatment covariates. This is confirmed by the data. A different fraction was randomized into treatment in each county. See Table 1.

${ }^{5}$ Of course, these individuals could participate in non-GAIN employment-creating activities.

${ }^{6}$ More precisely, individuals were registered in the first quarter of experimental time. This means that in some cases the first quarter of experimental time in fact includes information one or two months prior to
} 
In the GAIN experiment, the treatment is participating in the GAIN program; the control is receiving standard AFDC benefits. The GAIN program works as follows: based on test results and an interview with a case manager, participants were assigned to one of two activities. Those deemed not to be in need of basic education were referred to a job search activity (which lasts about three weeks); those who did not find work were placed in job training (which included vocational or on-the-job training and paid or unpaid work experience, lasting about three to four months). Those deemed to be in need of basic education could choose to enter job search immediately, but if they failed to find a job they were required to register for preparation toward the General Educational Development certificate, Adult Basic Education, or English as a Second Language programs (lasting three to four months). ${ }^{7}$ Participants were exempted from the requirement to participate in GAIN activities if they found work on their own. ${ }^{8}$

The counties in the GAIN experiment varied along two important dimensions. First, the composition of program participants varied, because counties chose to focus on particular subsets of their welfare populations and the populations differed. For example, Alameda and Los Angeles counties confined themselves to the subset of long-term

the commencement of the experiment. So for example, for an individual who attended an orientation session in February 1989, the first quarter of experimental time is from January to March 1989. Of course, some part of the first and second quarters could be spent participating in treatment activities. Pre-treatment data would cover the ten quarters from July 1986 to December 1988.

${ }^{7}$ The public use data do not contain information on each individual's participation in the various components of the program. At the same time, individuals in the control group can participate in non-GAIN activities. Thus, the treatment effect measures the increase in earnings, employment, etc., from the availability of and encouragement (or requirement) to use GAIN-related activities compared to pre-existing employment services.

${ }^{8}$ Note that only about eight-five per cent of the treated units actively participated in any GAIN activities (though by virtue of being in the GAIN sample they did attend an orientation meeting); the balance satisfied the requirements of the GAIN program on their own (in most cases finding employment within the first two or three quarters of experimental time). Thus, as observed earlier, this is important in interpreting the treatment effect as a comparison between earnings, employment, etc., when individuals are required to find a job or to participate in GAIN-related activities and when they are not obliged to find jobs and only pre-existing employment-related services are available. 
welfare recipients (individuals having already received welfare for two years or more).

The second difference is that the sub-treatment offered within each county varied due to differences in administrative philosophy. The approach followed by Riverside, which has received much attention, was to focus on job, rather than skills, acquisition. Both are part of the program, but Riverside's emphasis was the former. Instead counties like Alameda focused more on skill acquisition. The model will allow for differences in composition by conditioning on pre-treatment covariates and differences in the treatment by allowing for site effects.

\section{The GAIN Data}

Table 1 presents the six counties that participated in the GAIN experiment, broken down in terms of their 24 administrative sites. The counties vary from one-site counties such as Alameda to multi-site counties such as Los Angeles and San Diego. This paper will analyze the results at the site level because with six counties there is minimal scope for modeling site effects. Table 2 presents the background characteristics of each site in greater detail. We note that the average number of children varies from over four in some sites (site 21) to slightly over two in others (site 6). The proportion of Hispanics in the sample varies from a low of 6 per cent (site 1) to over 50 per cent in other sites (sites 14 and 24).

Table 2 shows that there is significant variation in the treatment impact across sites. The second to last column presents the average quarterly post-treatment earnings for the treatment and control groups. The treatment impact ranges from a high of $\$ 212$ for Site 5 (in Riverside county) to a low of $-\$ 132$ for Site 17 (in Tulare). In the last column 
the treatment effect is estimated conditioning on pre-treatment covariates through an OLS regression. The estimates are similar, ranging from $-\$ 90$ to $\$ 292$. The sites consistently showing the highest and most significant impacts are those from Riverside county (sites 2 to 5). Their treatment impacts range from $\$ 149$ to $\$ 292$, and are significantly different from zero. The worst performing county is Tulare, for which some of the impacts are negative and all are statistically insignificant.

\section{The Econometric Model}

A feature of the data which influences the modeling strategy is the large proportion of zeros in the outcome, earnings. With as many as 75 per cent of the outcomes being zero, the model must explicitly account for the mass point in the earnings distribution. The model has two components. The first is a probit model that determines the probability of positive earnings. The second, conditional on positive earnings, uses a hierarchical model, which is outlined below (see Dehejia [1999], which uses a similar model).

\subsection{The Probit Model}

Let $Y_{i t}$ denote earnings, for $i=1, \ldots, N$, and $t=1, \ldots, \tau$. $Y_{i t}{ }^{*}=0$ if $Y_{i t}=0$, and $=1$ if $Y_{i t}>0$. The probit model defines a latent variable such that $Y_{i t}{ }^{*}=0$ if $Y_{i t}{ }^{* *}<0,=1$ if $Y_{i t}{ }^{* *}>0$. The latent variable is assumed to follow a normal likelihood:

$$
Y_{i t}^{* *}\left\{Y_{i t}^{*}=y_{i t}^{*}\right\}_{t=1}^{t-1},\left\{X_{i t}=x_{i t}\right\}_{t=1}^{t}, \beta \sim N\left(x_{i t} \beta, 1\right)
$$

where $x_{i t}=\left[e_{i t} T_{i} e_{i t} S_{i t}\right], T_{i}$ is a treatment indicator ( $=1$ if treated, $=0$ otherwise), $e_{i t}=\left[Y_{i, t-1}\right.$ $\left.c_{i t}\right], c_{i t}$ is a vector of exogenous pre-treatment variables, and $S_{i t}$ is a set of site-level characteristics. Rather than using maximum likelihood to obtain a point estimate, we use 
a Gibbs sampling procedure to obtain the posterior distribution of the parameters (see Appendix A; also Albert and Chib [1993], Gelfland and Smith [1990], and Tanner and Wong [1987]). Though this is not a fully hierarchical model, it does allow for a restrictive form of site effects through the site characteristics.

\subsection{The Hierarchical Model}

The hierarchical model (see Gelman, Carlin, Stern, and Rubin [1996]) is a generalization of the regression model that allows each site to have its own value for the coefficients:

$$
Y_{i t j} \mid\left\{x_{i t j}\right\}_{\forall i, t, j} \beta_{j}, \sigma^{2} \sim N\left(\beta_{j}{ }^{\prime} x_{i t j}, \sigma^{2}\right)
$$

where $x_{i j t}$ is defined as in the previous section, except that we index the site as well, $j=1, \ldots, J$. Let $\beta_{j}{ }^{\prime}=\left(\beta_{j 1} \cdots \beta_{j M}\right)$, where $m=1, \ldots, M$ indexes the regressors. The model assumes a constant variance across sites. The key feature of the model is that the $\beta$ 's are linked through a further model:

$$
\beta_{j m} \mid\left\{z_{j}\right\}_{j=1}^{J}, \gamma_{m}, \Sigma \sim N\left(\gamma_{m}{ }^{\prime} z_{j}, \Sigma\right)
$$

where $z_{j}$ are a set of site characteristics used to model the site coefficients. The model for $\beta$ serves as a prior distribution with respect to the base model for earnings. The model is completed by defining priors for the parameters:

$$
\begin{gathered}
1 / \sigma^{2} \sim W_{1}\left(r, Q^{-1}\right), \\
\Sigma^{-1} \sim W\left(\rho, K^{-1}\right),
\end{gathered}
$$

and

$$
\operatorname{vec}(\gamma) \sim N(d, \Sigma \otimes D)
$$


The prior on $\Sigma^{-1}$ determines the degree of smoothing the model performs. The estimate of the $\beta$ 's for each site are a precision-weighted average of the OLS estimates within each site and the $\beta$ 's predicted by the model in (3). The weight, in turn, is influenced by the prior for $\Sigma^{-1}$. The Wishart prior can be interpreted as $\rho$ previous observations with variance $K$. When $K$ reflects high variance, this will pull up the estimate of $\Sigma$, and lead to a greater weight being placed on the common prior for $\beta$ 's and a lower weight on the $\beta$ estimated within each site. Estimation is again undertaken using a Gibbs sampler (outlined in Appendix B).

\subsection{The Predictive Distribution}

Since the object of interest for the policy question is earnings, and only indirectly the parameters, we generate the predictive distribution, the distribution in the space of outcomes that captures all of the uncertainty from the model, both intrinsic uncertainty and parameter uncertainty. This distribution is simulated by repeatedly drawing for parameter values from their posterior distribution and then drawing from the outcome distribution conditional on observed data and parameters.

\section{The Results}

The model outlined in the previous section is implemented on the GAIN data, using age, education, number and age of children, previous participation in a training program, reading and writing test scores, ethnicity, and pre-treatment earnings as pre-treatment individual characteristics. These are interacted with the treatment indicator, so that the model allows for the site effect for treatment in control earnings to be different. The mean 
characteristics of participants (including the mean number of children, mean reading score, mean level of education, mean age, and mean pre-treatment earnings) are used as the site characteristics. The Gibbs samplers outlined in the appendices produce estimates of the posterior distribution of the parameters. These are then used to produce a predictive distribution of earnings (under treatment and control) for each individual. The predictive distributions are then averaged over the individuals at a site to produce an estimate of the site impact.

Tables 3 to 5 present the treatment impact for the 24 sites in the GAIN data with a pooled regression model, correlated random effects, and a range of hierarchical models. Note that the same probit model is used as we vary the model for positive earnings.

\subsection{Are site effects important in this data?}

The first three sets of estimates in Table 3 allow us to consider to what extent site effects are obscured by pooling all observations. The pooled model (columns (1) and (2)) is a regression of positive earnings on a constant, pre-treatment covariates, and a treatment indicator (which is interacted with the covariates). Instead, the correlated random effects model (columns (3) and (4)) allows for a site-specific constant which depends on the mean characteristics of the participants within each site. The third set of estimates (columns (5) and (6)) is derived from the hierarchical framework, but ignores the metamodel that predicts site effects, focusing on the $\beta_{j}$ within each site. The prior variance on the $\beta$ 's, $K$, is specified to be very low (diagonal elements of $10^{-5}$ ), which means that the model engages in very minimal smoothing across sites. Each $\beta_{j}$ is virtually identical to the estimate that would be obtained within each site. 
In comparing the pooled estimates with those from the site-specific estimates (Figures 1 to 3), we observe that the results are broadly similar. For some sites (sites 1, 5, 18, and 23) the pooled estimates of earnings are within $\$ 20$ of the site-specific estimates. Many estimates are within $\$ 50$, and all sites (except 6 and 19) are within $\$ 100$ for both treatment and control earnings. In terms of the treatment impact, we note that the estimates are closer, with the biggest difference being $\$ 87$ for site 11 (in San Diego). The estimated treatment impact from the correlated random effects models is even closer to the treatment impacts estimated within each site. The comparison suggests that pooling the data is not especially misleading in estimating the treatment impact for each site, and that most of the differences across sites in treatment impacts are accounted for by differences in the composition of participants (see also Hotz, Imbens, and Klerman 2000).

A more direct way to examine the importance of site effects is to vary the smoothing parameter in the hierarchical model The previous comparisons suggest that pooling the data (hence including out-of-site observations in the regression) does not significantly alter the estimated treatment effect. This is seen directly in Table 3 , columns (7) and (8) (and Figure 4), in which the estimates of the hierarchical model with an extremely high degree of smoothing are presented; the elements of $K$ are set to $10^{6}$ along its diagonal. In the table and figure we note that the estimates are extremely similar when a high or low degree of smoothing is used, with all differences less than $\$ 20$. In principle, by choosing an intermediate value for the smoothing prior we could achieve an intermediate degree of smoothing, but in this case clearly the results would not differ substantially. Thus for these data the question of how much smoothing to use is not a 
central one. Of course for other data sets the question could more substantial, and the ability to control the degree of smoothing would be more valuable.

\subsection{Could site effects be important in other settings? Is there predictive uncertainty?}

In the previous results, average earnings at each site are estimated using different individuals at the different sites. Instead, in Table 4, columns (1) and (2), we examine the average earnings of the same individuals (participants from site 19, Alameda) when assigned to the different sites. The other sites' characteristics and the site coefficients are predicted using the characteristics of the individuals who originally participated in the program at that site. The thought experiment is to determine earnings for Alameda participants if, for example, they had entered the program in the environment of Riverside. As we vary the characteristics of the site we can see that there is variation in both estimated earnings and the treatment impact for these individuals (see Figure 5). The level of treatment (control) earnings varies from $\$ 158$ (\$122) in site 2 (site 2) to $\$ 948$ (\$787) in site 14 (site 14). The treatment effect varies from $\$ 52$ in sites 2 and 13 to $\$ 293$ in site 6. Even though the pooled model yields an accurate prediction for the treatment impact of site 19 participants when they are assigned to site 19, when we imagine reassigning the same individuals to other sites, the site effect becomes important. Depending on which Riverside site the Alameda participants were assigned to, their treatment impact could be substantially higher or substantially lower.

Site effects can also be important for their predictive uncertainty. If we were to reimplement the GAIN program, how accurately could we predict what would happen at a given site? The second set of estimates in Table 4 (columns (3) and (4)) predict the site- 
specific parameters based on each site's characteristics. These are then used to predict the outcome for participants at each site. The relevant comparison is to the estimates in Table 3 , columns (5) and (6), which ignore uncertainty in the site effects. The immediate observation is that the results are quite similar, always within $\$ 100$ and typically within $\$ 40$. At one level this may seem trivial: since the data for a given site are included in the estimation, it may not seem surprising that we are able to predict its outcome with accuracy. The result is not trivial because for each site we draw new site parameters based on the hierarchical model and base predictions on these. So, for example, when we predict the outcome for site 6 , the characteristics of the program participants in site 6 imply a set of site characteristics, which in turn produce a set of site parameters that lead to the average earnings we estimate.

However, we note that the range of uncertainty increases significantly (see Figures 6 and 7). Though the 95 percent posterior probability intervals of the estimates in Table 4, columns (3) and (4) (depicted in Figure 6) rarely fully overlap with the intervals in Table 3, columns (5) and (6), they are substantially wider. The increased uncertainty is meaningful in the sense that the treatment impact for many sites ceases to be significant. In the context of Table 3, in columns (5) and (6), we note that for 8 of the sites the 95 percent probability intervals for treatment and control earnings do not overlap, indicating a significant treatment impact, whereas this is true for only 4 sites in Table 4, columns (3) and (4). For example, for sites 2, 3, and 4 (the Riverside sites) in Table 3, columns (5) and (6), the posterior 95 percent probability intervals do not overlap, but they do in Table 4, columns (7) and (8). Overall the comparison of the two sets of estimates suggests that when the site-specific parameters are re-estimated for each site, we succeed in replicating 
a profile of outcomes similar to those that are obtained for each site in isolation.

However, uncertainty increases, and in some cases significantly.

\subsection{Predicting site effects}

The next question relating to site effects is whether we would be able to predict the outcomes at a site if we had not observed it in our data. To explore this issue the estimates in Table 5, columns (1) and (2), drop each site successively and use the remaining sites to predict its outcome. The results are close to those in Table 3, columns (5) and (6), where the site data is included, within $\$ 30$ for most site, except sites 3 to 5 (Riverside) and site 24 which are within $\$ 75$. An important qualification to this result is that, even though we are excluding the site for which we are predicting the outcome, we include other sites from the county. Would it be possible to estimate the profile of treatment effects across sites if we exclude all of these observations from a county when estimating the model? The answer is presented in Table 5, columns (3) and (4) (and Figure 8). For most sites the predictions are worse than when other sites within the county are included, though with some exceptions the model is still able to predict the overall profile of treatment effects. The exceptions are the Riverside and Los Angeles sites.

The failure accurately to predict the treatment effects for these sites illustrates the limitation of any model in extrapolating or predicting the treatment impact at a site that is significantly different from the sites observed in the sample. The Los Angeles sites differ substantially in terms of the number of children, which is higher than at other sites, and pre-treatment earnings, which are lower than at other sites. An estimator or a functional 
form that is more flexible in terms of pre-treatment covariates should yield a more reliable prediction of the treatment impact. For example, propensity score estimates (see Dehejia and Wahba [1999] and Heckman, Ichimura, and Todd [1998]) of the treatment impact for sites 20 to 24 (see Figure 8), range from $\$ 121$ to $\$ 217$, which are closer to the actual impacts than the estimates from the simple linear hierarchical model. ${ }^{9}$ In contrast, the Riverside sites do not stand out in terms of their pre-treatment site characteristics. The differences with other sites seem to be along other, presumably qualitative, dimensions of the treatment applied. When the propensity score estimator is applied to the Riverside sites (see Figure 8), the estimated treatment impacts still underestimate the true treatment effects, confirming that differences in observable characteristics do not account for the underprediction. This inability to predict the Riverside treatment effects supports the view that Riverside differed from other counties in the approach it took to administering the treatment. Predictions based on other sites consistently under-estimate the treatment impacts in Riverside.

\section{Conclusions}

This paper has addressed three questions: (1) To what extent do site-specific effects matter in predicting the outcome for a given site? (2) Does predictive uncertainty regarding site effects influence the interpretation of the treatment effect? and (3) Would we be able to predict the outcome for a site, if its data were not observed. The answer to the first question is that, once we have accounted for differences in the composition of program participants across sites, site-specific effects are not especially important in

\footnotetext{
${ }^{9}$ This estimator controls for pre-treatment covariates through the estimated propensity score. Since the estimated propensity score is a single variable we can allow for a flexible functional form more easily. The
} 
predicting the outcome a given site for the GAIN data. By pooling data together, we only minimally distort the outcome for a particular site. Different degrees of smoothing across sites were explicitly considered and were found to have little impact on the estimated treatment effect, which reinforced this conclusion. The second and third questions are different because they deal with predictive uncertainty for subsequent implementations of the program. When making in-sample predictions, the model is able to predict the profile of site effects with reasonable accuracy. This amounts to saying that even the simple set of site-level characteristics that are used in the hierarchical model are sufficient to identify the distinct profile of site impacts in the GAIN data. However, we also find that the predictive uncertainty is significant: the treatment effect for many sites ceases to be significant when predictive uncertainty is incorporated into the estimate. Finally, when making out-of-sample predictions, the quality of the prediction was found to depend upon observing a sufficient number of sites similar to the site for which predictions are being made. For example, when dropping even some of the Riverside sites, the quality of the predictions for Riverside sites declines. This is not true for the Los Angeles sites when dropped singly, but is also becomes true when all of the observations from Los Angeles are excluded.

Was there a Riverside miracle? The received wisdom regarding the GAIN program is that qualitative site-specific factors played an important role. Indeed the MDRC reports its findings separately for each county. The results presented here suggest that a simple set of site characteristics are sufficient to distinguish the various site-level effects. To this extent, there was nothing miraculous about Riverside. However the results also suggest that substantial extrapolation from the existing sites that are observed 
to new sites can potentially be misleading. For example, the Riverside treatment effects are consistently under-predicted when excluding data from all Riverside sites. Thus, more precisely, there is nothing miraculous about Riverside if one observes similar sites in the data. However, in the absence of data on similar sites, Riverside is difficult to predict and is a miracle to that extent.

There are a number of possible extensions to this work. First, the set of site characteristics used were rudimentary, and could in principle be extended to include features of the local labor market or perhaps even characteristics of the program administrators. It would be interesting to discover how much additional precision could be obtained. Second, the true economic significance of the different predictions from the range of models can only be assessed if they are linked to a decision problem. Would the added uncertainty when predicting site-level effects be sufficient to alter the policymaker's decision regarding which program to choose? These are questions for on-going research. 


\section{References}

Albert, J. and S. Chib (1993). "Bayesian Analysis of Binary and Polychotomous Response Data," Journal of the American Statistical Association, 88, 669-679.

Riccio, James, Daniel Friedlander, and Stephen Freedman (1994). GAIN: Benefits, Costs, and Three-Year Impacts of a Welfare-to-Work Program. New York: Manpower Demonstration Research Corporation.

Card, David, and Alan Krueger (1992). "Does School Quality Matter? Returns to Education and the Characteristics of Public Schools in the United States," Journal of Political Economy, 100, 1-40.

Chamberlain, Gary, and Guido Imbens (1996). "Hierarchical Bayes Models with Many Instrumental Variables," Harvard Institute of Economic Research, Paper Number 1781.

Cooper, Harris, and Larry Hedges (1994), editors. The Handbook of Research Synthesis. New York: Russell Sage Foundation.

Dehejia, Rajeev (1999). "Program Evaluation as a Decision Problem," National Bureau of Economic Research Working Paper No. 6954.

and Sadek Wahba (1999). "Causal Effects in Non-Experimental Studies:

Reevaluating the Evaluation of Training Programs," Journal of the American Statistical Association, Volume 94, pp. 1053-1062.

Gelfland, A.E., and A.F.M. Smith (1990), "Sampling-Based Approaches to Calculating Marginal Densities," Journal of the American Statistical Association, 85, 398-409.

Gelman, Andrew, John Carlin, Hal Stern, and Donald Rubin (1996). Bayesian Data Analysis. London: Chapman and Hall.

Geweke, John, and Michael Keane (1996). "An Empirical Analysis of the Male Income Dynamics in the PSID: 1968-1989," Journal of Econometrics, 96, 293-356.

Greenberg, David, and Michael Wiseman (1992). "What Did the OBRA Demonstrations Do?” Chapter 1, in Manski and Garfinkel (1992).

Heckman, James, and Jeffrey Smith (1996). "The Sensitivity of Experimental Impact Estimates: Evidence from the National JTPA Study," University of Western Ontario, unpublished.

------, H. Ichimura, and P. Todd (1998). "Matching as an Econometric Evaluation Estimator," Review of Economic Studies, 65, 261-294. 
Hotz, V. Joseph, Guido Imbens, and Julie Mortimer (1999). "Predicting the Efficacy of Future Training Programs Using Past Experiences," National Bureau of Economic Research Working Paper, No. T238.

------, ------, and Jacob Klerman (2000). "The Long-Term Gains from GAIN: A ReAnalysis of the Impacts of the California GAIN Program," UCLA, unpublished.

Nelson, Doug (1997). "Some 'Best Practices' and 'Most Promising Models' for Welfare Reform," Memorandum, Annie E. Casey Foundation, Baltimore, MD; http://center.hamline.edu/mcknight/caseymemo.htm.

Manski, Charles, and Irwin Garfinkel (1992), editors. Evaluating Welfare Training Programs. Cambridge, MA: Harvard University Press.

Rossi, Peter, Robert McCulloch, and Greg Allenby (1995). "Hierarchical Modeling of Consumer Heterogeneity: An Application to Target Marketing," in C. Gatsonis, J. Hodges, R. Kass, and N. Singpurwalla (eds.), Case Studies in Bayesian Statistics, Volume II, Lecture Notes in Statistics, 105. New York: Springer-Verlag.

Tanner, M., and W. Wong (1987). "The Calculation of Posterior Distributions by Data Augmentation," Journal of the American Statistical Association, 82, 528-550. 


\section{Appendix A: Probit Model}

Given diffuse priors for $\beta$ and an arbitrary starting value $\beta^{(0)}$, the Gibbs sampling scheme is:

(1) Conditional on $\beta^{(j)}$, draw values for $y_{i t}{ }^{* *}$ : for $\left\{i t: y_{i t}{ }^{*}=0\right\}$, from the negative portion of a normal distribution with mean $x_{i t} \beta^{(j)}$ and variance 1, and for $\left\{i t: y_{i t}{ }^{*}=1\right\}$, from the positive portion of the same distribution. Denote the filled-in dependent variable $y_{i t, Z}^{(j+1)}$, so that $y_{i, Z}^{(j+1)}=\left(y_{i 1, Z}^{(j+1)} \ldots y_{i \tau, Z}^{(j+1)}\right)^{\prime}$.

(2) Conditional on $Y_{Z}^{(j+1)}=\left(Y_{1 Z}^{(j+1)}, \ldots, Y_{I Z}^{(j+1)}\right)^{\prime \prime}$, draw for $\beta^{(j+1)}$ from

$$
N\left(\hat{\beta}^{(j+1)},\left(X^{\prime} X\right)^{-1}\right),
$$

where $\hat{\beta}^{(j+1)}=\left(X^{\prime} X\right)^{-1} X^{\prime} Y_{Z}^{(j+1)}$, with $X_{i}=\left(x_{i 1}{ }^{\prime} \ldots x_{i \tau}{ }^{\prime}\right)^{\prime}$, and $X=\left(X_{1}{ }^{\prime}, \ldots, X_{I}^{\prime}\right)^{\prime}$.

From an arbitrary starting value, this is iterated 2000 times, producing $\left(Y_{Z}^{(j)}, \beta^{(j)}\right)$.

The first 500 iterations are discarded, leaving 1500 draws from posterior distribution of the parameters, which will be indexed $j=1, \ldots, 1500$.

\section{Appendix B: The Hierarchical Model}

(1) $\beta_{j}^{(l)} \sim N\left(\bar{\beta}_{j}, V_{\beta}^{(l-1)}\right)$, where $\bar{\beta}_{j}=\left(X_{j}{ }^{\prime} X_{j} \sigma_{(l-1)}^{-2}+\Sigma_{(l-1)}^{-1}\right)^{-1}\left(X_{j}{ }^{\prime} X_{j} \sigma_{(l-1)}^{-2} \hat{\beta}+\Sigma_{(l-1)}^{-1} \beta^{p}\right)$, $\hat{\beta}=\left(X_{j}{ }^{\prime} X_{j}\right)^{-1} X_{j}{ }^{\prime} y_{j}, \beta^{p}=\gamma_{(l-1)}^{\prime} z_{j}$, and $V_{\beta}=\left[X_{j}{ }^{\prime} X_{j} \sigma_{(l-1)}^{-2}+\Sigma_{(l-1)}^{-1}\right]^{-1}$,

(2) $1 / \sigma_{(l-1)}^{2} \sim \chi_{(n+r)}^{2} /\left(Q^{-1}+s^{2}\right)$, where $\left[s_{i t j}\right]=y_{i j}-\beta_{j}^{(l)} x_{i t j}$ and $s^{2}=s^{\prime} s$,

(3) $\Sigma_{(l)}^{-1} \sim W\left(J-M+\rho,\left(S+K^{-1}\right)^{-1}\right)$, where $S=\sum_{t=1}^{J} e_{t}^{\prime} e_{t}$ and $e_{t}=\beta_{t}-\gamma_{t} z_{t}$ (the Mx1 vector of residuals for each site observation),

(4) $\gamma^{(l)} \sim N\left(\widetilde{\gamma}, \Sigma_{(l)} \otimes\left(Z^{\prime} Z+D^{-1}\right)^{-1}\right)$, where $\gamma=\left(\gamma_{1} \cdots \gamma_{M}\right)^{\prime}, \widetilde{\gamma}=\operatorname{vec}(\bar{\gamma})$, $\bar{\gamma}=\left(\left(Z^{\prime} Z\right)+D^{-1}\right)^{-1}\left(Z^{\prime} Z \hat{\gamma}+D^{-1} d\right)$, and $\hat{\gamma}_{j}=\left(z_{j}^{\prime} z_{j}\right)^{-1} z_{j}^{\prime} \beta_{j}$.

This procedure produces a sequence of draws from the parameters, the first 500 of which we discard, leaving us with draws from the posterior distribution of the parameters. 
Table 1: The Sample

\begin{tabular}{lcccccc}
\hline \hline & Alameda & Butte & $\begin{array}{c}\text { Los } \\
\text { Angeles }\end{array}$ & Riverside & $\begin{array}{c}\text { San } \\
\text { Diego }\end{array}$ & Tulare \\
\hline GAIN: & & & & & & \\
Treated Group & 685 & 1717 & 3730 & 5808 & 8711 & 2693 \\
Control Group & 682 & 458 & 2124 & 1706 & 1810 & 1146 \\
Total & 1367 & 2175 & 5854 & 7514 & 10521 & 3839 \\
Number of Sites & 1 & 1 & 5 & 4 & 8 & 5
\end{tabular}

Notes: The GAIN sample sizes are from the public use file of the GAIN data. The AFDC total represents the number of AFDC cases (both single-parent and two-parent households) in the six evaluation counties in December 1990 (see Riccio, et al. (1994), Table 1.1). 
Table 2: Site Characteristics and Outcomes from the GAIN Experiment

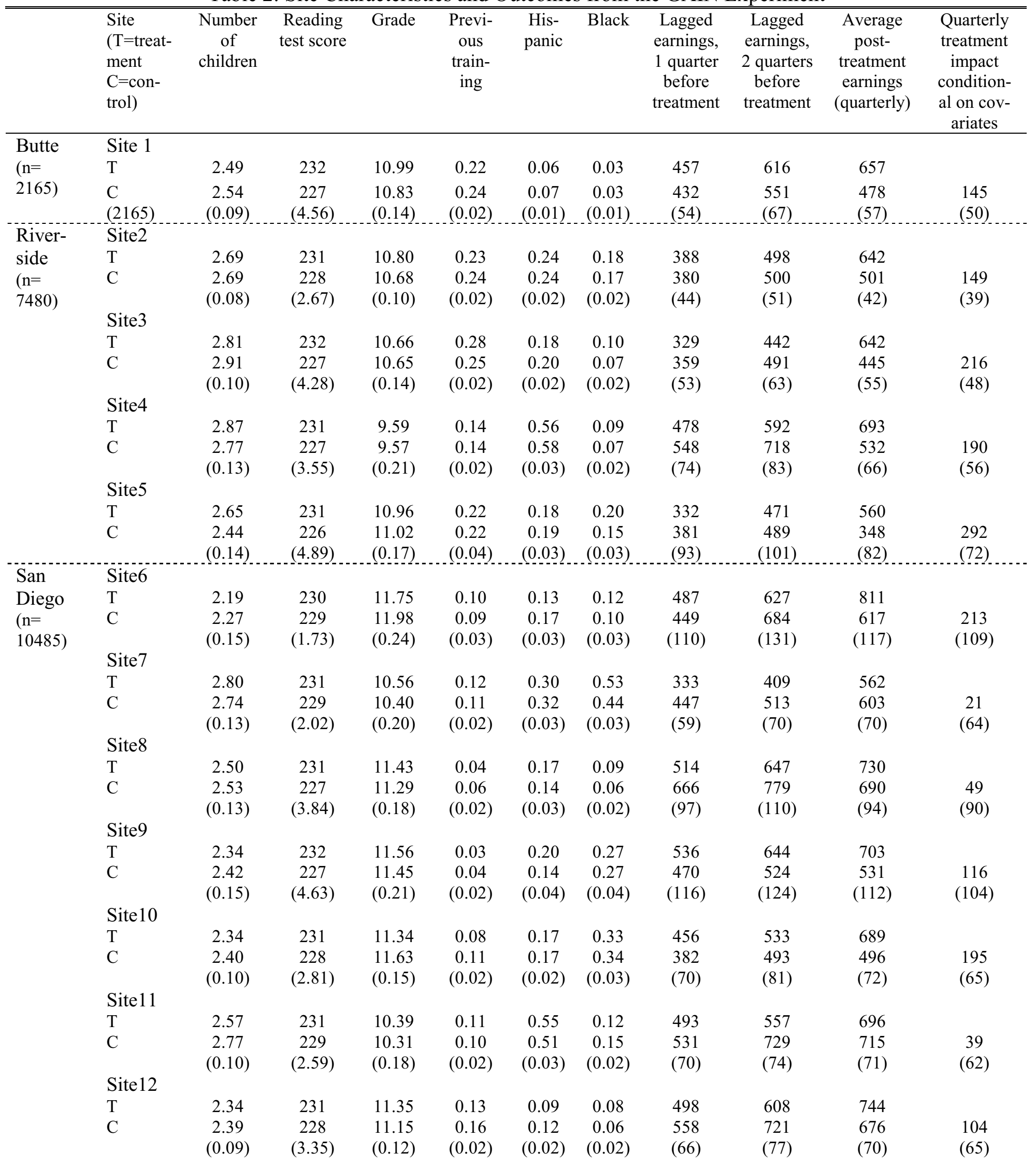


Table 2: Site Characteristics and Outcomes from the GAIN Experiment (continued)

\begin{tabular}{|c|c|c|c|c|c|c|c|c|c|c|c|}
\hline "County & $\begin{array}{l}\text { Site } \\
(\mathrm{T}=\text { treat- } \\
\text { ment } \\
\mathrm{C}=\text { con- } \\
\text { trol) }\end{array}$ & $\begin{array}{c}\text { Number } \\
\text { of } \\
\text { children }\end{array}$ & $\begin{array}{l}\text { Reading } \\
\text { tests core }\end{array}$ & "Grade & $\begin{array}{l}\text { Previ- } \\
\text { ous } \\
\text { train- } \\
\text { ing }\end{array}$ & $\begin{array}{l}\text { His- } \\
\text { panic }\end{array}$ & Black & $\begin{array}{c}\text { Lagged } \\
\text { earnings, } \\
1 \text { period } \\
\text { before } \\
\text { treatment }\end{array}$ & $\begin{array}{c}\text { Lagged } \\
\text { earnings, } \\
2 \text { periods } \\
\text { before } \\
\text { treatment }\end{array}$ & $\begin{array}{c}\text { Average } \\
\text { post- } \\
\text { treatment } \\
\text { earnings } \\
\text { (quarterl } \\
\text { y) } \\
\end{array}$ & $\begin{array}{c}\text { Quarterly } \\
\text { treatment } \\
\text { impact } \\
\text { condition- } \\
\text { al on cov- } \\
\text { ariates } \\
\end{array}$ \\
\hline San & Site13 & & & & & & & & & & \\
\hline \multirow{2}{*}{$\begin{array}{l}\text { Diego } \\
\text { (cont'd) }\end{array}$} & $\mathrm{T}$ & 3.92 & 231 & 6.45 & 0.12 & 0 & 0.00 & 298 & 321 & 414 & \\
\hline & $\mathrm{C}$ & $\begin{array}{c}4.44 \\
(0.25)\end{array}$ & $\begin{array}{c}228 \\
(2.61)\end{array}$ & $\begin{array}{c}7.03 \\
(0.44) \\
\end{array}$ & $\begin{array}{c}0.12 \\
(0.03)\end{array}$ & $\begin{array}{c}0 \\
(0)\end{array}$ & $\begin{array}{c}0 \\
(0.01)\end{array}$ & $\begin{array}{l}234 \\
(55)\end{array}$ & $\begin{array}{r}205 \\
(60) \\
\end{array}$ & $\begin{array}{r}455 \\
(84) \\
\end{array}$ & $\begin{array}{l}-90 \\
(77)\end{array}$ \\
\hline \multirow{18}{*}{$\begin{array}{l}\begin{array}{l}\text { Tulare } \\
(\mathrm{n}=\end{array} \\
3835)\end{array}$} & Site 14 & & & & & & & & & & \\
\hline & $\mathrm{T}$ & 2.87 & 230 & 9.63 & 0.06 & 0.62 & 0.01 & 476 & 603 & 610 & \\
\hline & C & $\begin{array}{c}3.02 \\
(0.19)\end{array}$ & $\begin{array}{l}227 \\
(2.7)\end{array}$ & $\begin{array}{c}9.50 \\
(0.32)\end{array}$ & $\begin{array}{c}0.08 \\
(0.03)\end{array}$ & $\begin{array}{c}0.63 \\
(0.05)\end{array}$ & $\begin{array}{c}0.01 \\
(0.01)\end{array}$ & $\begin{array}{c}527 \\
(103)\end{array}$ & $\begin{array}{c}513 \\
(104)\end{array}$ & $\begin{array}{l}641 \\
(96)\end{array}$ & $\begin{array}{l}-15 \\
(87)\end{array}$ \\
\hline & Site15 & & & & & & & & & & \\
\hline & $\mathrm{T}$ & 3.03 & 232 & 9.45 & 0.25 & 0.43 & 0 & 573 & 665 & 612 & \\
\hline & C & $\begin{array}{c}3.33 \\
(0.20)\end{array}$ & $\begin{array}{c}226 \\
(5.47)\end{array}$ & $\begin{array}{c}9.21 \\
(0.33)\end{array}$ & $\begin{array}{c}0.22 \\
(0.04)\end{array}$ & $\begin{array}{c}0.49 \\
(0.05)\end{array}$ & $\begin{array}{c}0.01 \\
(0.01)\end{array}$ & $\begin{array}{c}366 \\
(103)\end{array}$ & $\begin{array}{c}435 \\
(112)\end{array}$ & $\begin{array}{l}515 \\
(87)\end{array}$ & $\begin{array}{c}25 \\
(77)\end{array}$ \\
\hline & Site16 & & & & & & & & & & \\
\hline & $\mathrm{T}$ & 3.04 & 231 & 9.47 & 0.25 & 0.34 & 0.01 & 439 & 521 & 530 & \\
\hline & C & 3.05 & 228 & 9.38 & 0.20 & 0.29 & 0.01 & 440 & 530 & 444 & 80 \\
\hline & & $(0.14)$ & $(3.23)$ & $(0.22)$ & $(0.03)$ & $(0.03)$ & $(0.01)$ & (67) & (74) & (61) & (53) \\
\hline & Site17 & & & & & & & & & & \\
\hline & $\mathrm{T}$ & 2.98 & 232 & 10.08 & 0.26 & 0.40 & 0.11 & 403 & 504 & 558 & \\
\hline & $\mathrm{C}$ & 3.05 & 226 & 10.36 & 0.19 & 0.38 & 0.09 & 597 & 716 & 691 & -18 \\
\hline & & $(0.15)$ & (6.29) & $(0.20)$ & $(0.03)$ & (0.04) & $(0.02)$ & (74) & (92) & (75) & (68) \\
\hline & Site18 & & & & & & & & & & \\
\hline & $\mathrm{T}$ & 3.04 & 231 & 9.91 & 0.12 & 0.36 & 0.02 & 544 & 598 & 578 & \\
\hline & C & 3.06 & 228 & 9.77 & 0.11 & 0.38 & 0.03 & 475 & 518 & 590 & -2 \\
\hline & & $(0.14)$ & (3.85) & $(0.26)$ & $(0.02)$ & $(0.04)$ & $(0.01)$ & (100) & (104) & (79) & (62) \\
\hline \multirow{4}{*}{$\begin{array}{l}\text { Alamed } \\
\mathrm{a} \\
(\mathrm{n}= \\
1360)\end{array}$} & Site19 & & & & & & & & & & \\
\hline & $\mathrm{T}$ & 2.38 & 231 & 10.78 & 0.23 & 0.09 & 0.63 & 139 & 118 & 377 & \\
\hline & C & 2.39 & 228 & 10.80 & 0.25 & 0.06 & 0.65 & 145 & 141 & 301 & 84 \\
\hline & & $(0.09)$ & $(3.01)$ & $(0.16)$ & $(0.02)$ & $(0.01)$ & $(0.03)$ & $(33)$ & (30) & (46) & (41) \\
\hline \multirow{20}{*}{$\begin{array}{l}\text { Los } \\
\text { Angeles } \\
(\mathrm{n}= \\
5850)\end{array}$} & Site20 & & & & & & & & & & \\
\hline & $\mathrm{T}$ & 3.54 & 232 & 9.36 & 0.20 & 0.40 & 0.11 & 136 & 145 & 381 & \\
\hline & C & 3.44 & 223 & 9.55 & 0.14 & 0.30 & 0.13 & 160 & 157 & 301 & 108 \\
\hline & & $(0.16)$ & $(8.63)$ & $(0.25)$ & $(0.03)$ & $(0.03)$ & $(0.02)$ & (34) & (36) & (52) & (49) \\
\hline & Site21 & & & & & & & & & & \\
\hline & $\mathrm{T}$ & 4.20 & 230 & 7.84 & 0.11 & 0.28 & 0.09 & 178 & 193 & 340 & \\
\hline & $\mathrm{C}$ & 4.45 & 228 & 7.38 & 0.12 & 0.24 & 0.07 & 199 & 178 & 253 & 80 \\
\hline & & $(0.18)$ & (2.32) & $(0.27)$ & $(0.02)$ & $(0.03)$ & $(0.02)$ & (31) & (34) & (40) & (37) \\
\hline & Site22 & & & & & & & & & & \\
\hline & $\mathrm{T}$ & 3.21 & 230 & 9.54 & 0.05 & 0.22 & 0.47 & 175 & 179 & 301 & \\
\hline & C & 3.25 & 227 & 9.17 & 0.05 & 0.18 & 0.41 & 173 & 162 & 311 & -6 \\
\hline & & $(0.12)$ & (3.68) & $(0.20)$ & $(0.01)$ & $(0.02)$ & $(0.03)$ & (33) & (32) & (43) & (39) \\
\hline & Site23 & & & & & & & & & & \\
\hline & $\mathrm{T}$ & 3.72 & 231 & 9.69 & 0.17 & 0.15 & 0.64 & 165 & 139 & 309 & \\
\hline & $\mathrm{C}$ & 4.07 & 229 & 9.49 & 0.15 & 0.16 & 0.56 & 146 & 121 & 299 & -7 \\
\hline & & $(0.11)$ & (1.5) & $(0.17)$ & $(0.02)$ & $(0.02)$ & $(0.02)$ & (30) & (26) & (36) & (32) \\
\hline & Site24 & & & & & & & & & & \\
\hline & $\mathrm{T}$ & 3.73 & 231 & 7.61 & 0.16 & 0.78 & 0.06 & 62 & 67 & 210 & \\
\hline & C & 3.84 & 228 & 7.39 & 0.17 & 0.73 & 0.06 & 137 & 152 & 269 & -50 \\
\hline & & $(0.17)$ & (3.13) & $(0.29)$ & $(0.03)$ & (0.03) & $(0.02)$ & (33) & (37) & (46) & (44) \\
\hline
\end{tabular}


Table 3: Estimated Site Earnings (Quarterly)

\begin{tabular}{|c|c|c|c|c|c|c|c|c|c|}
\hline \multicolumn{2}{|l|}{$\begin{array}{l}\text { Coun- } \\
\text { ty }\end{array}$} & \multicolumn{2}{|c|}{ Pooled } & \multicolumn{2}{|c|}{$\begin{array}{l}\text { Correlated Random } \\
\text { Effects }\end{array}$} & \multicolumn{2}{|c|}{$\begin{array}{l}\text { Hierarchical Model, No } \\
\text { smoothing }\end{array}$} & \multicolumn{2}{|c|}{$\begin{array}{l}\text { Hierarchical Model, } \\
\text { Maximum smoothing }\end{array}$} \\
\hline \multirow[b]{2}{*}{ Butte } & & (1) & (2) & (3) & (4) & (5) & (6) & (7) & (8) \\
\hline & $\begin{array}{l}\text { Site } \\
1\end{array}$ & $\begin{array}{c}\text { Treatment } \\
668 \\
{[641,696]}\end{array}$ & $\begin{array}{c}\text { Control } \\
541 \\
{[512,571]}\end{array}$ & $\begin{array}{c}\text { Treatment } \\
659 \\
{[631,686]}\end{array}$ & $\begin{array}{c}\text { Control } \\
541 \\
{[513,572]}\end{array}$ & $\begin{array}{c}\text { Treatment } \\
651 \\
{[609,691]}\end{array}$ & $\begin{array}{c}\text { Control } \\
521 \\
{[483,566]}\end{array}$ & $\begin{array}{c}\text { Treatment } \\
650 \\
{[615,690]}\end{array}$ & $\begin{array}{c}\text { Control } \\
522 \\
{[487,563]}\end{array}$ \\
\hline \multirow[t]{6}{*}{$\begin{array}{l}\text { River } \\
\text {-side }\end{array}$} & Site2 & $\begin{array}{c}623 \\
{[599,645]}\end{array}$ & $\begin{array}{c}495 \\
{[472,518]}\end{array}$ & $\begin{array}{c}609 \\
{[586,630]}\end{array}$ & $\begin{array}{c}492 \\
{[469,515]}\end{array}$ & $\begin{array}{c}569 \\
{[536,599]}\end{array}$ & $\begin{array}{c}491 \\
{[458,524]}\end{array}$ & $\begin{array}{c}568 \\
{[539,595]}\end{array}$ & $\begin{array}{c}495 \\
{[467,523]}\end{array}$ \\
\hline & Site3 & $\begin{array}{c}587 \\
{[562,615]}\end{array}$ & $\begin{array}{c}463 \\
{[437,489]}\end{array}$ & $\begin{array}{c}570 \\
{[545,598]}\end{array}$ & $\begin{array}{c}457 \\
{[432,484]}\end{array}$ & $\begin{array}{c}620 \\
{[580,664]}\end{array}$ & $\begin{array}{c}503 \\
{[458,551]}\end{array}$ & $\begin{array}{c}603 \\
{[568,641]}\end{array}$ & $\begin{array}{c}486 \\
{[447,527]}\end{array}$ \\
\hline & Site & 622 & 519 & 619 & 526 & 678 & 514 & 648 & 507 \\
\hline & 4 & {$[587,657]$} & {$[487,551]$} & {$[584,654]$} & {$[493,557]$} & {$[626,727]$} & {$[466,565]$} & {$[606,693]$} & {$[467,550]$} \\
\hline & Site & $629^{\circ}$ & 492 & 658 & 523 & $633^{\circ}$ & 496 & 578 & 461 \\
\hline & 5 & {$[581,678]$} & {$[449,533]$} & {$[608,709]$} & {$[477,568]$} & {$[566,702]$} & {$[428,575]$} & {$[525,637]$} & {$[411,517]$} \\
\hline \multirow{16}{*}{$\begin{array}{l}\text { San } \\
\text { Diego }\end{array}$} & Site & 724 & $575^{\circ}$ & 761 & 614 & 824 & 697 & 770 & 616 \\
\hline & 6 & {$[674,774]$} & {$[536,624]$} & {$[708,813]$} & {$[573,668]$} & {$[746,904]$} & {$[593,809]$} & {$[702,840]$} & {$[541,698]$} \\
\hline & Site & 555 & 444 & 524 & 428 & 504 & 451 & 495 & 431 \\
\hline & 7 & {$[523,586]$} & {$[414,478]$} & {$[495,553]$} & {$[399,461]$} & {$[463,543]$} & {$[404,499]$} & {$[458,534]$} & {$[389,475]$} \\
\hline & Site & 714 & 576 & 724 & $594^{\circ}$ & 651 & 531 & 675 & 549 \\
\hline & 8 & {$[677,756]$} & {$[538,614]$} & {$[687,768]$} & {$[554,633]$} & [599,709] & {$[474,594]$} & {$[630,723]$} & {$[501,602]$} \\
\hline & Site & $692^{\circ}$ & 554 & 681 & 554 & 663 & 507 & 642 & 492 \\
\hline & 9 & {$[640,748]$} & {$[508,603]$} & {$[628,735]$} & {$[508,603]$} & {$[589,738]$} & {$[424,592]$} & {$[578,707]$} & {$[429,565]$} \\
\hline & Site & 641 & 507 & 672 & 540 & 624 & 453 & 605 & 437 \\
\hline & 10 & {$[610,673]$} & {$[478,535]$} & {$[639,705]$} & {$[509,570]$} & {$[580,667]$} & {$[408,498]$} & {$[568,642]$} & {$[405,475]$} \\
\hline & Site & 645 & 528 & 673 & 560 & 694 & 664 & 690 & 636 \\
\hline & 11 & {$[614,676]$} & {$[502,553]$} & {$[640,704]$} & {$[532,586]$} & {$[650,743]$} & {$[612,722]$} & {$[652,730]$} & {$[591,681]$} \\
\hline & Site & 704 & 564 & 735 & 598 & 723 & 576 & 719 & 572 \\
\hline & 12 & {$[671,735]$} & {$[534,594]$} & {$[700,767]$} & {$[566,631]$} & {$[673,774]$} & {$[529,628]$} & {$[679,762]$} & {$[530,619]$} \\
\hline & Site & 404 & 319 & 339 & 274 & 465 & 442 & $497^{-}$ & 430 \\
\hline & 13 & {$[367,442]$} & {$[286,353]$} & $308,371]$ & {$[246,304]$} & {$[406,529]$} & {$[369,533]$} & {$[445,558]$} & {$[363,501]$} \\
\hline \multirow{10}{*}{$\begin{array}{l}\text { Tu- } \\
\text { lare }\end{array}$} & Site & 646 & 549 & 631 & 546 & 584 & 575 & 581 & 545 \\
\hline & 14 & [585,710] & [498,599] & {$[572,692]$} & {$[496,597]$} & {$[512,661]$} & {$[494,670]$} & {$[523,644]$} & {$[487,607]$} \\
\hline & Site & 642 & 527 & 653 & 545 & 573 & 489 & 607 & 515 \\
\hline & 15 & {$[589,697]$} & {$[477,579]$} & {$[599,708]$} & {$[494,601]$} & {$[501,657]$} & {$[416,566]$} & {$[548,670]$} & {$[453,585]$} \\
\hline & Site & 602 & 497 & 596 & 500 & 573 & 491 & 588 & 504 \\
\hline & 16 & {$[564,639]$} & {$[463,534]$} & {$[559,633]$} & {$[466,537]$} & {$[515,627]$} & {$[436,545]$} & {$[542,635]$} & {$[457,557]$} \\
\hline & Site & 652 & 537 & 652 & $545^{-}$ & 592 & 538 & 614 & 550 \\
\hline & 17 & {$[610,699]$} & {$[497,576]$} & {$[610,698]$} & {$[505,586]$} & {$[533,651]$} & {$[484,597]$} & {$[563,664]$} & {$[501,602]$} \\
\hline & Site & 644 & 524 & 686 & 569 & 607 & 522 & 605 & 526 \\
\hline & 18 & {$[599,695]$} & {$[485,568]$} & $638,741]$ & {$[526,617]$} & {$[539,678]$} & {$[460,590]$} & {$[557,657]$} & {$[473,584]$} \\
\hline \multirow{12}{*}{$\begin{array}{l}\text { Ala- } \\
\text { meda } \\
\text { LosAn } \\
\text {-geles }\end{array}$} & Site & $457^{-}$ & 328 & 412 & $302^{-}$ & 304 & 211 & $335^{\circ}$ & 233 \\
\hline & 19 & {$[427,491]$} & {$[301,356]$} & $384,442]$ & {$[277,327]$} & $269,341]$ & {$[183,239]$} & {$[303,371]$} & {$[209,261]$} \\
\hline & Site & 410 & 322 & $355^{-1}$ & 287 & 347 & 230 & 361 & 254 \\
\hline & 20 & {$[373,447]$} & {$[290,354]$} & {$[324,386]$} & {$[258,315]$} & {$[301,394]$} & {$[196,266]$} & {$[324,401]$} & {$[219,289]$} \\
\hline & Site & 386 & 317 & 287 & 243 & 303 & 259 & 302 & 265 \\
\hline & 21 & $352,421]$ & {$[284,348]$} & $263,313]$ & {$[218,267]$} & $266,343]$ & {$[221,301]$} & {$[268,334]$} & {$[233,300]$} \\
\hline & Site & 395 & 308 & 341 & 273 & $333^{\circ}$ & 285 & 332 & 281 \\
\hline & 22 & $369,424]$ & {$[282,334]$} & $318,366]$ & {$[250,296]$} & {$[297,371]$} & {$[251,321]$} & {$[301,365]$} & {$[251,315]$} \\
\hline & Site & 380 & 282 & 337 & 257 & 344 & 286 & 345 & 283 \\
\hline & 23 & $356,403]$ & {$[260,306]$} & $317,357]$ & {$[237,279]$} & {$[315,377]$} & {$[256,318]$} & {$[317,376]$} & {$[254,316]$} \\
\hline & Site & 321 & 254 & 274 & 223 & 349 & 343 & 314 & 311 \\
\hline & 24 & {$[288,357]$} & {$[224,286]$} & {$[246,305]$} & {$[196,251]$} & {$[293,405]$} & {$[287,398]$} & {$[274,358]$} & {$[265,362]$} \\
\hline
\end{tabular}


Table 4: Estimated Site Earnings (Quarterly)

\begin{tabular}{llccc}
\hline $\begin{array}{l}\text { Coun- } \\
\text { ty }\end{array}$ & \multicolumn{2}{c}{$\begin{array}{c}\text { Alameda Participants in } \\
\text { Other Sites }\end{array}$} & \multicolumn{2}{c}{ Hierarchical Model, } \\
Predicting Site Effect
\end{tabular}


Table 5: Estimated Site Earnings (Quarterly)

\begin{tabular}{|c|c|c|c|c|c|}
\hline \multirow[t]{2}{*}{$\begin{array}{l}\text { Coun- } \\
\text { ty }\end{array}$} & & \multicolumn{2}{|c|}{$\begin{array}{l}\text { Predicting site effect, } \\
\text { dropping that site }\end{array}$} & \multicolumn{2}{|c|}{$\begin{array}{l}\text { Dropping all sites for that } \\
\text { county }\end{array}$} \\
\hline & & (1) & (2) & (3) & (4) \\
\hline Butte & $\begin{array}{l}\text { Site } \\
1\end{array}$ & $\begin{array}{c}\text { Treatment } \\
660 \\
{[605,718]}\end{array}$ & $\begin{array}{c}\text { Control } \\
533 \\
{[475,598]}\end{array}$ & $\begin{array}{c}\text { Treatment } \\
660 \\
{[605,718]}\end{array}$ & $\begin{array}{c}\text { Control } \\
533 \\
{[475,598]}\end{array}$ \\
\hline \multirow{8}{*}{$\begin{array}{l}\text { River } \\
\text {-side }\end{array}$} & Site 2 & 578 & 486 & 532 & 492 \\
\hline & & {$[523,640]$} & {$[429,542]$} & {$[456,617]$} & {$[407,590]$} \\
\hline & Site3 & 511 & 439 & 488 & 460 \\
\hline & & {$[456,566]$} & {$[388,497]$} & {$[411,571]$} & {$[380,566]$} \\
\hline & Site & 574 & 524 & 545 & 534 \\
\hline & 4 & {$[514,642]$} & {$[463,596]$} & {$[480,620]$} & {$[459,623]$} \\
\hline & Site & 606 & 524 & 558 & 522 \\
\hline & 5 & {$[538,685]$} & {$[458,602]$} & {$[469,659]$} & {$[429,645]$} \\
\hline \multirow{16}{*}{$\begin{array}{l}\text { San } \\
\text { Diego }\end{array}$} & Site & 689 & 531 & 652 & 511 \\
\hline & 6 & {$[610,784]$} & {$[452,626]$} & {$[487,876]$} & {$[369,697]$} \\
\hline & Site & 534 & 458 & 584 & 495 \\
\hline & 7 & {$[494,577]$} & {$[418,505]$} & {$[505,685]$} & {$[426,576]$} \\
\hline & Site & 707 & 580 & 710 & 583 \\
\hline & 8 & {$[633,783]$} & {$[517,650]$} & {$[566,875]$} & {$[466,736]$} \\
\hline & Site & 676 & 539 & 688 & 549 \\
\hline & 9 & {$[599,765]$} & {$[464,628]$} & {$[529,891]$} & {$[410,725]$} \\
\hline & Site & 615 & 485 & 603 & 475 \\
\hline & 10 & {$[563,665]$} & {$[435,535]$} & {$[488,757]$} & {$[375,597]$} \\
\hline & Site & 623 & 522 & 647 & 539 \\
\hline & 11 & {$[576,679]$} & {$[473,575]$} & {$[550,751]$} & {$[462,629]$} \\
\hline & Site & 696 & 549 & 669 & 535 \\
\hline & 12 & {$\left[641,76^{\circ}\right.$} & {$[501,601]$} & {$[541,821]$} & {$[427,665]$} \\
\hline & Site & 380 & 312 & 479 & 411 \\
\hline & 13 & {$[293,476]$} & {$[234,404]$} & {$[313,708]$} & {$[236,598]$} \\
\hline \multirow{10}{*}{$\begin{array}{l}\text { Tu- } \\
\text { lare }\end{array}$} & Site & 649 & 585 & 717 & 664 \\
\hline & 14 & {$[575,729]$} & {$[511,663]$} & {$[612,823]$} & {$[536,808]$} \\
\hline & Site & 649 & 592 & 731 & 666 \\
\hline & 15 & {$[576,724]$} & $520,670]$ & {$[631,846]$} & {$[563,783]$} \\
\hline & Site & 640 & 561 & 710 & 629 \\
\hline & 16 & {$[567,715]$} & {$[497,631]$} & {$[617,809]$} & {$[516,746]$} \\
\hline & Site & 673 & 580 & 764 & 672 \\
\hline & 17. & {$[605,747]$} & {$[501,663]$} & {$[665,870]$} & {$[551,811]$} \\
\hline & Site & 658 & 556 & 708 & 607 \\
\hline & 18 & {$[597,722]$} & {$[497,621]$} & {$[635,787]$} & {$[529,700]$} \\
\hline \multirow{12}{*}{$\begin{array}{l}\text { Ala- } \\
\text { meda } \\
\text { LosAn } \\
\text {-geles }\end{array}$} & Site & 499 & 344 & 499 & 344 \\
\hline & 19 & $380,621]$ & {$[250,451]$} & {$[380,621]$} & {$[250,45$} \\
\hline & Site & 343 & 282 & 486 & 501 \\
\hline & 20. & [296,394] & {$[237,331]$} & [319,714] & {$[287,787]$} \\
\hline & Site & 280 & 254 & 501 & 812 \\
\hline & 21 & {$[222,355]$} & {$[183,350]$} & {$[253,875]$} & {$[310]$,} \\
\hline & Site & 361 & 289 & 460 & 469 \\
\hline & 22 & {$[306,417]$} & {$[241,338]$} & {$[299,645]$} & {$[270,720]$} \\
\hline & Site & 552 & 408 & 592 & 576 \\
\hline & 23 & {$[454,676]$} & {$[313,508]$} & {$[386,856]$} & [316,933] \\
\hline & Site & 336 & 272 & 383 & 417 \\
\hline & 24 & {$[245,436]$} & {$[187,380]$} & {$[218,618]$} & {$[207,752]$} \\
\hline
\end{tabular}


Figure 1: Treatment Eamings

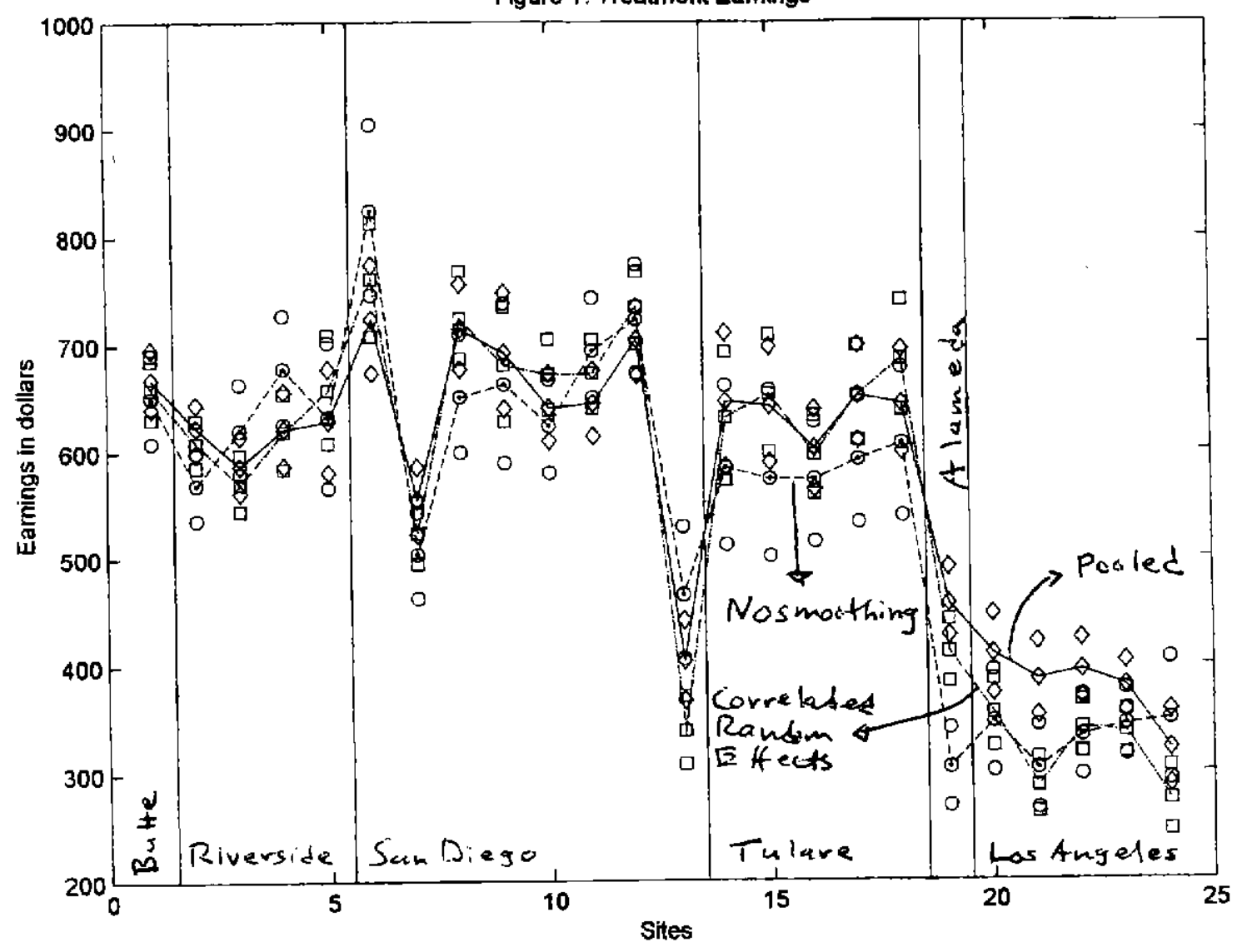


Figure 2: Control Eamings

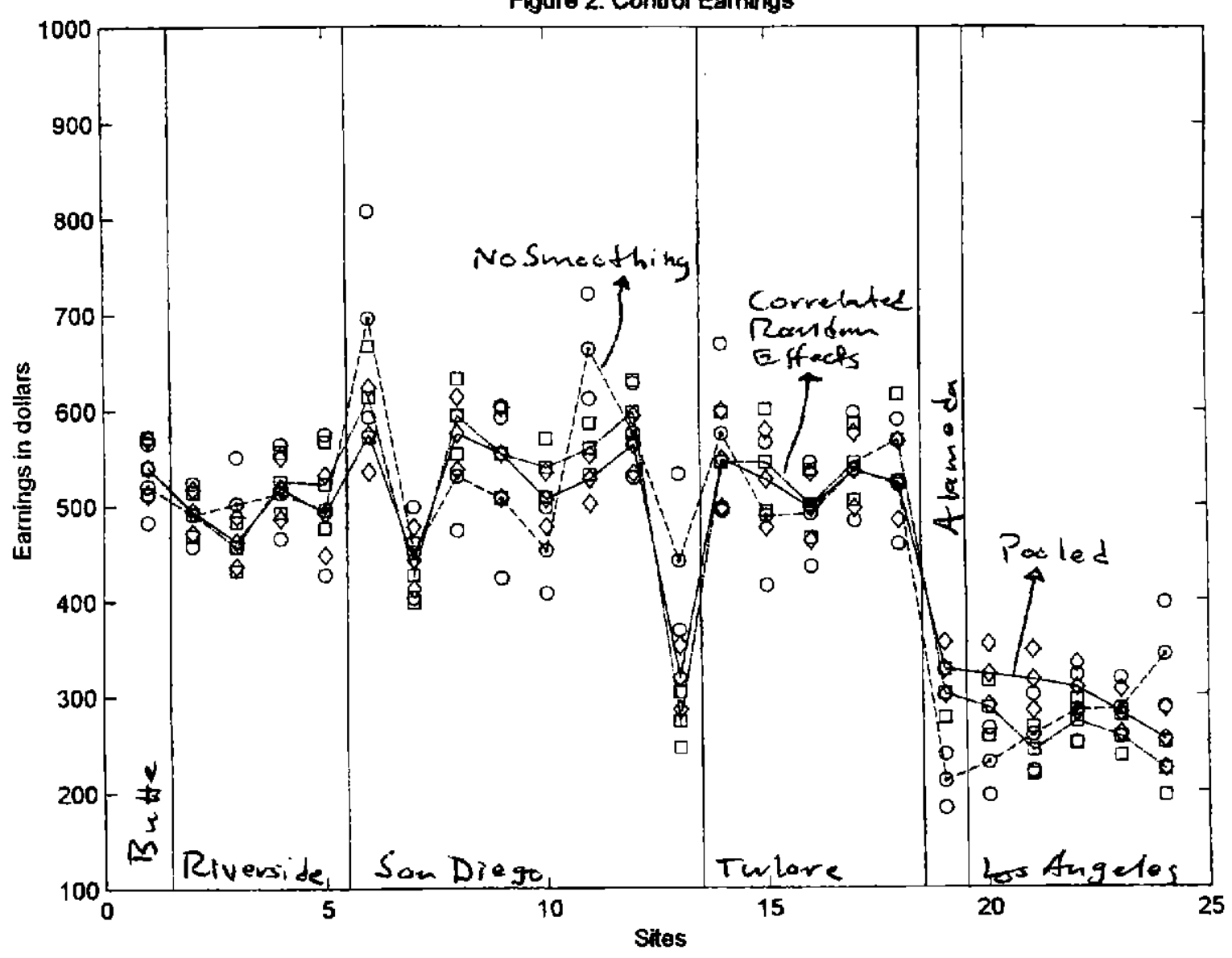


Figure 3: Treatment Effect

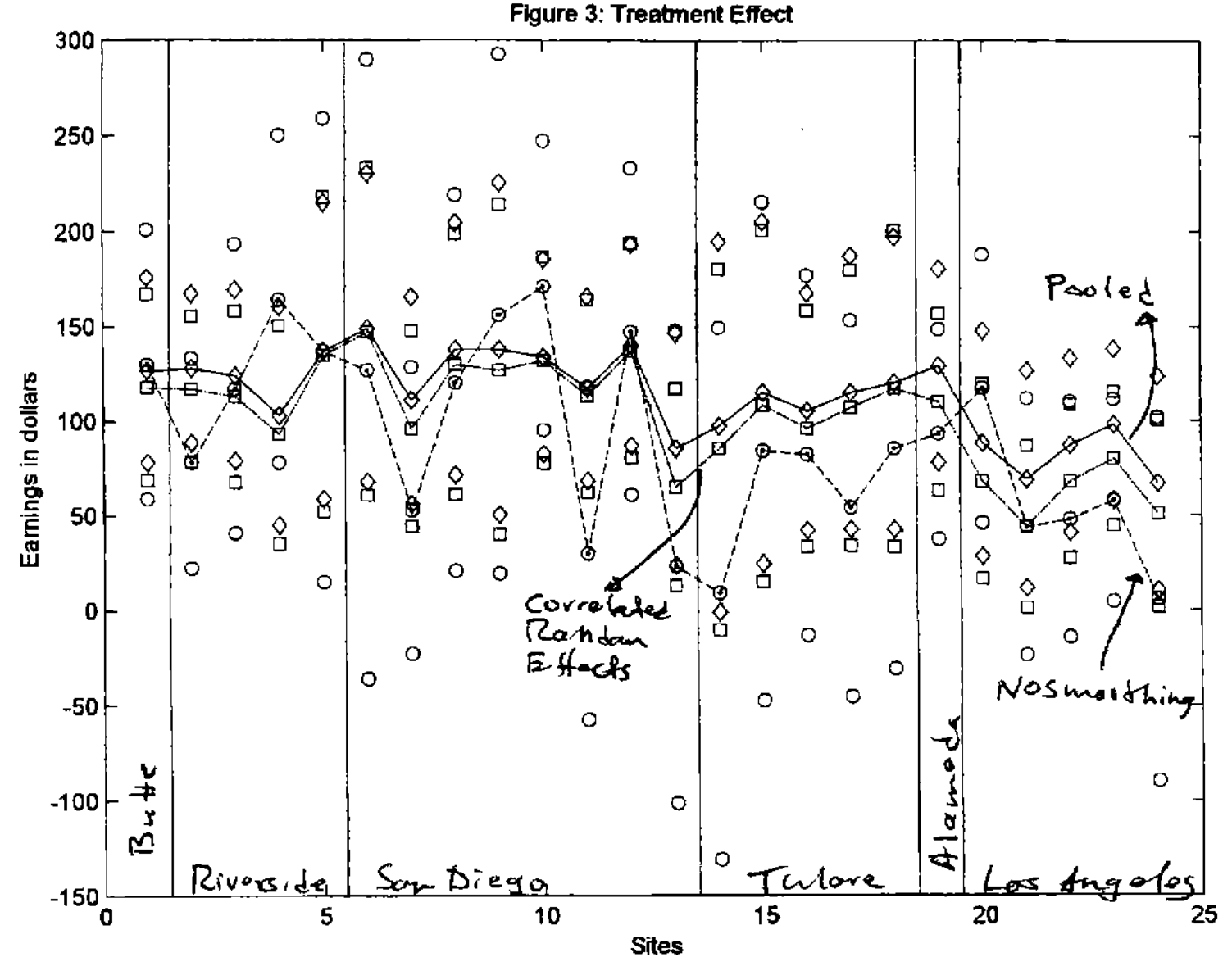


Figure 4: Treatment Effect

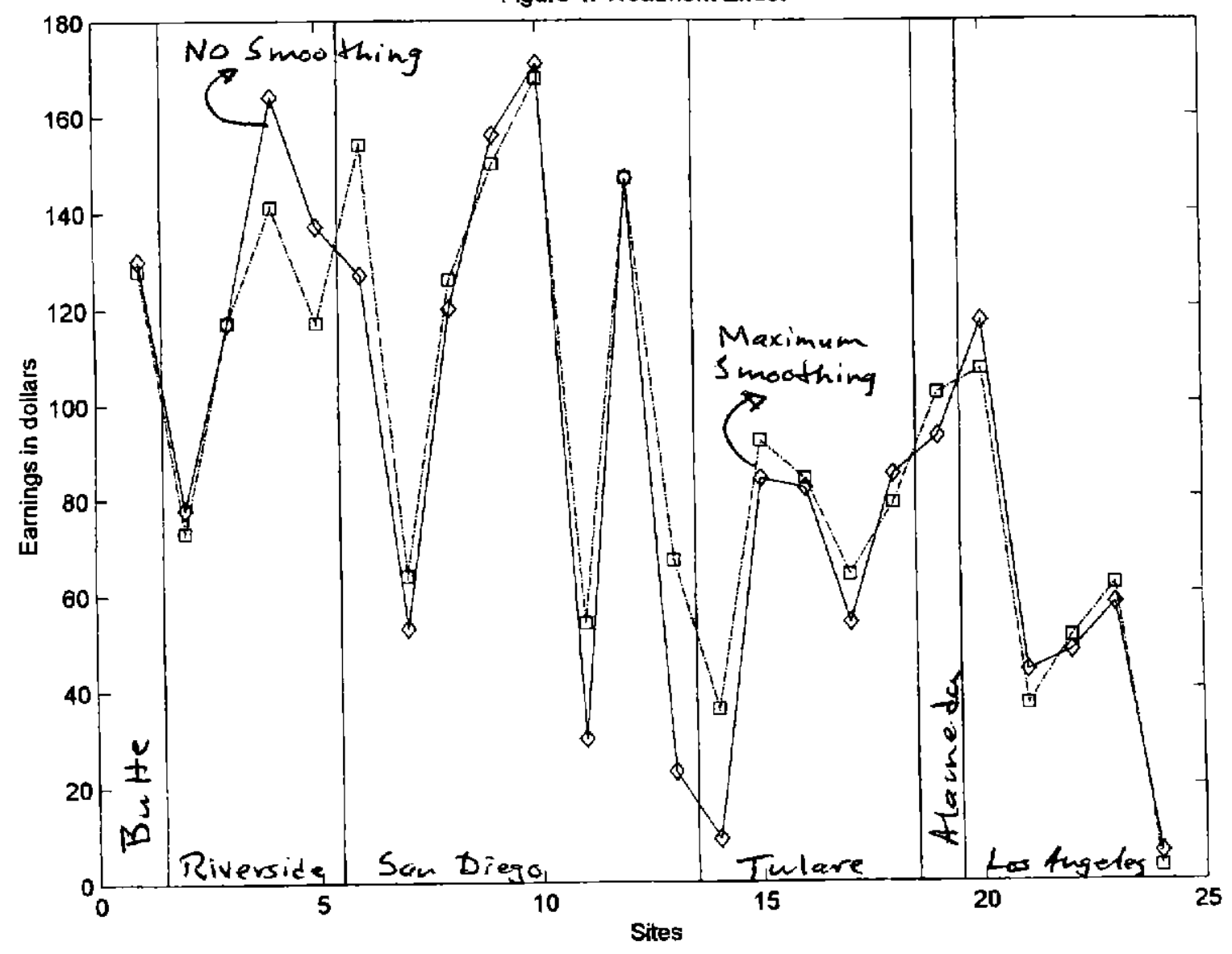




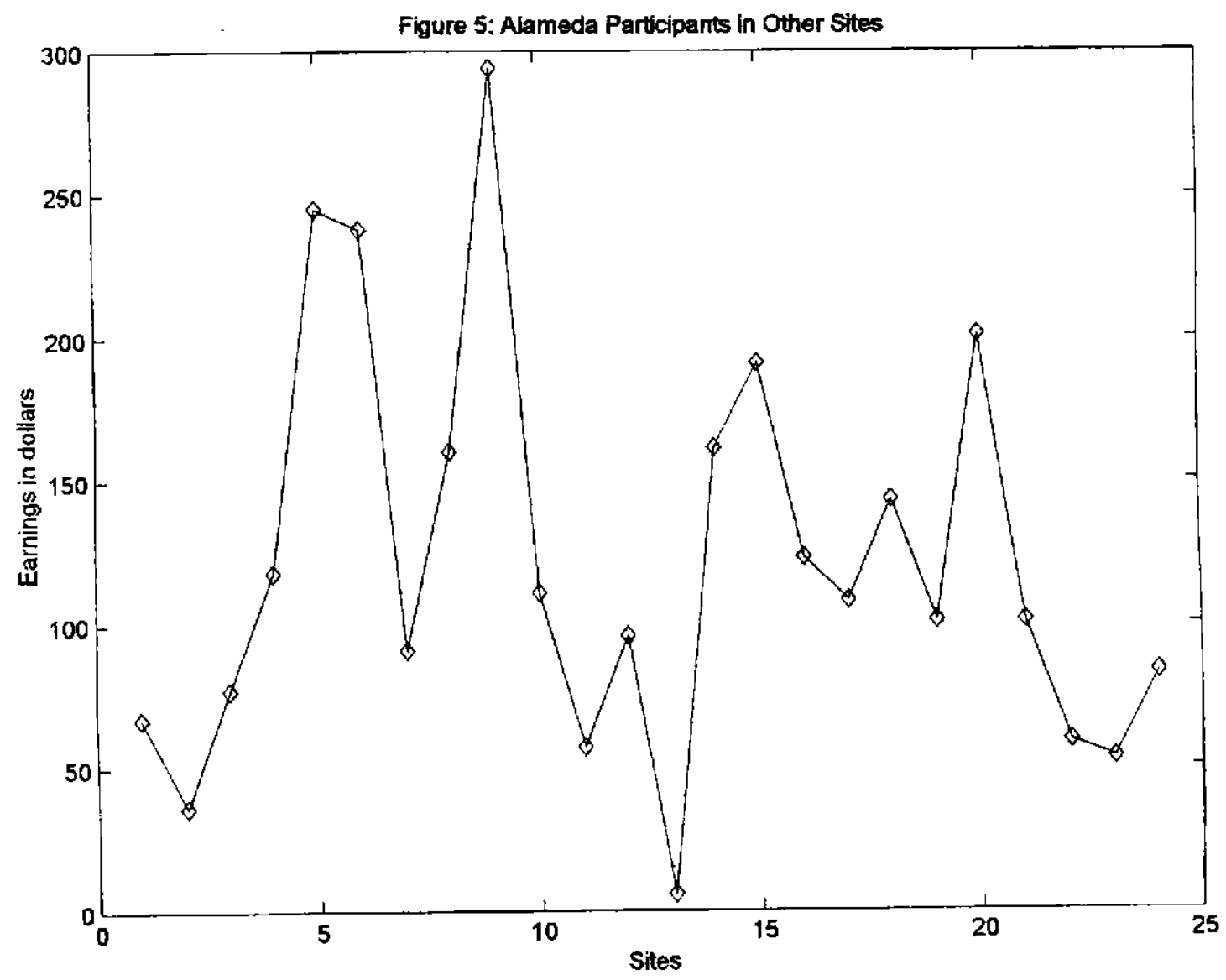


Figure 6: Treatment and Control Earnings, Given Site Effects

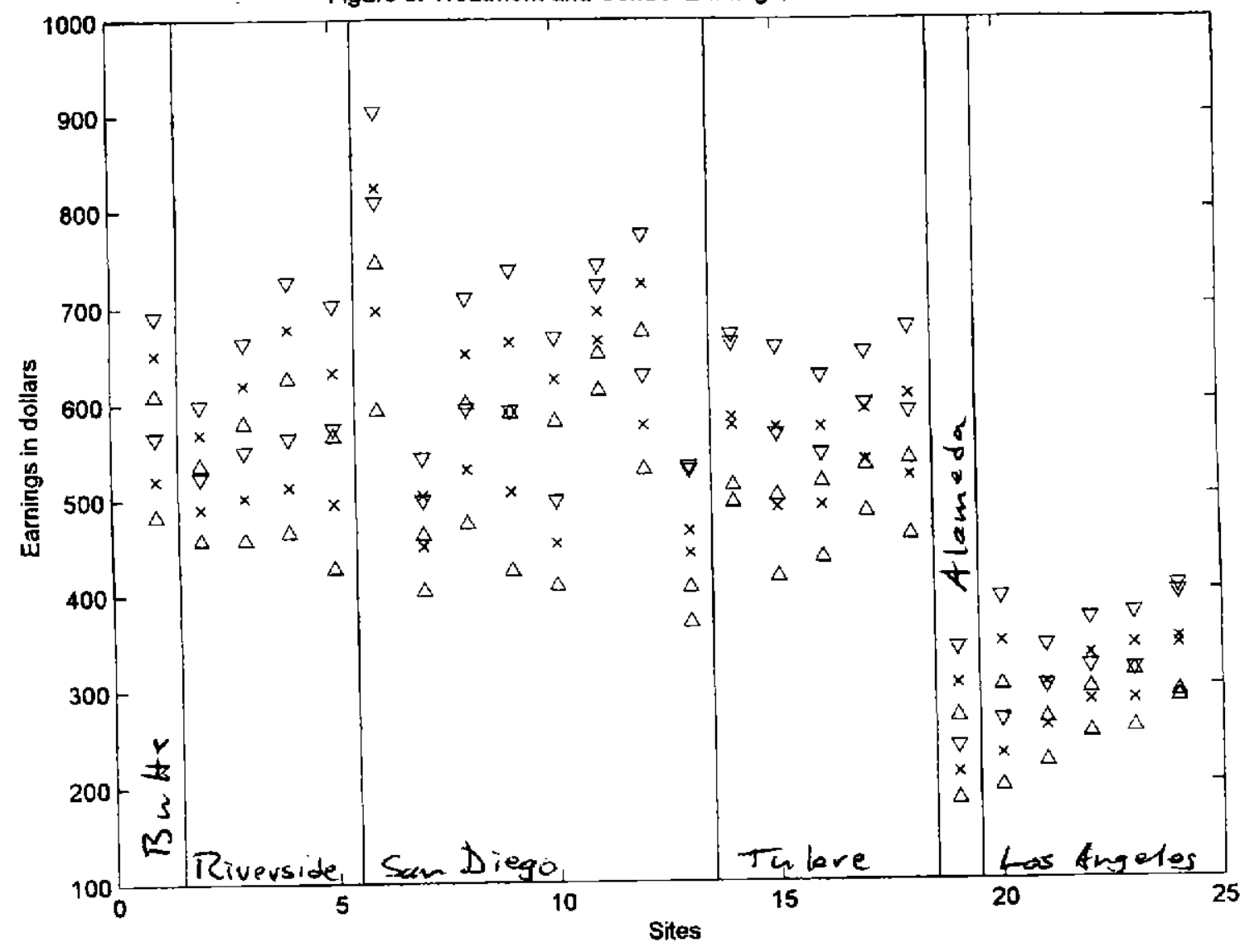


Figure 7: Treatment and Control Earnings, Predicting Site Effects

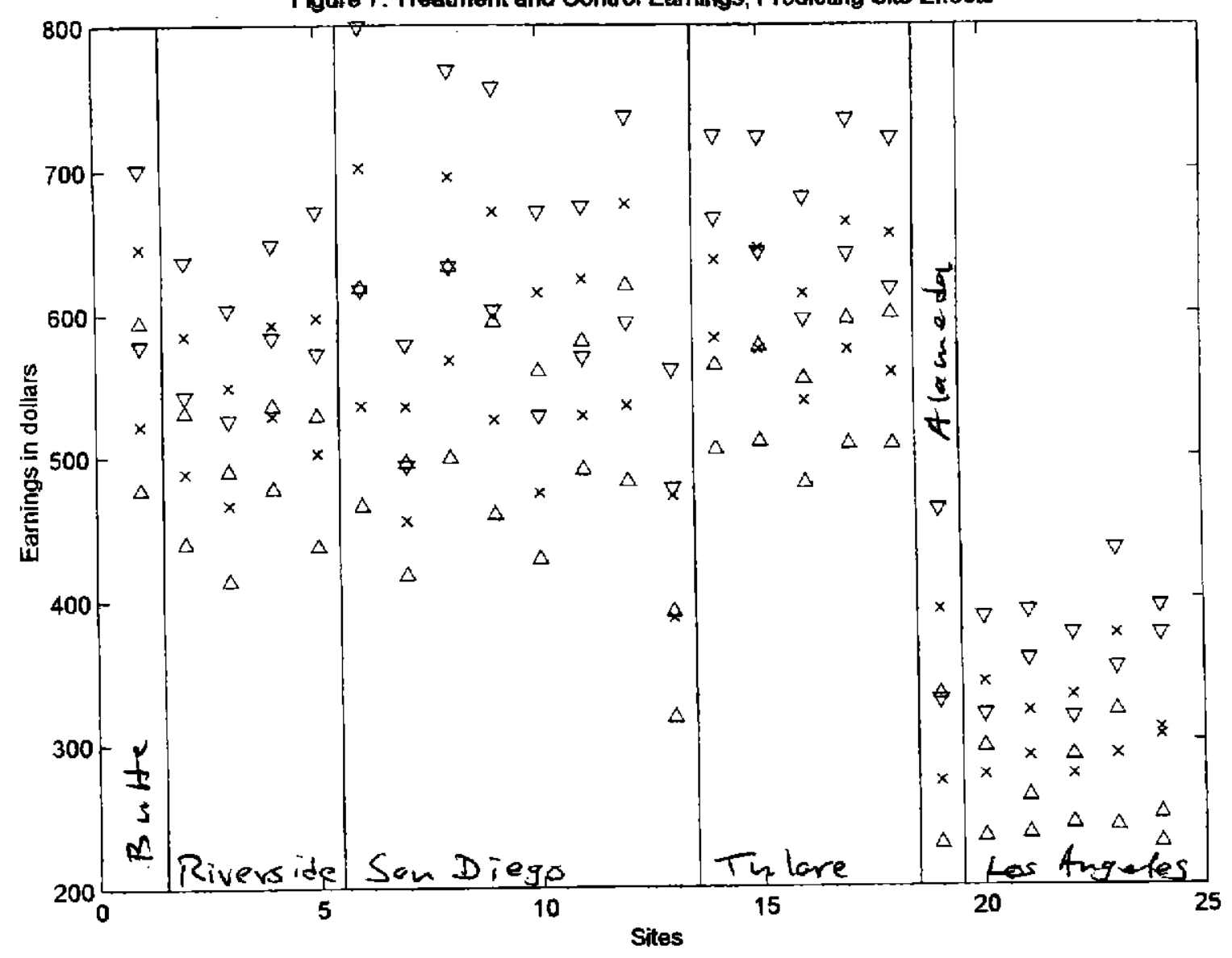


Figure 8: Predicting Site Effects

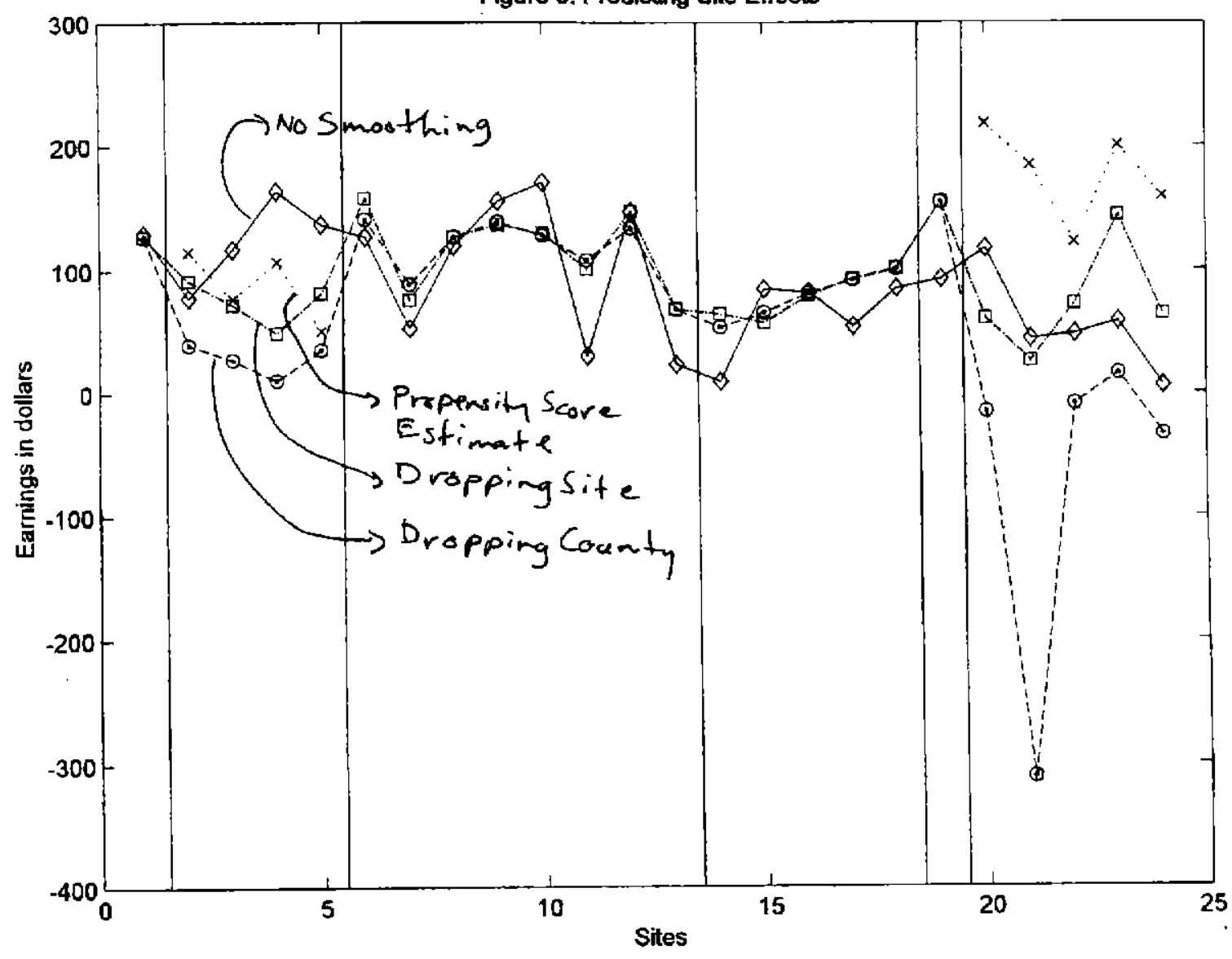

